\title{
Immunocytochemistry: A New Microwave Application
}

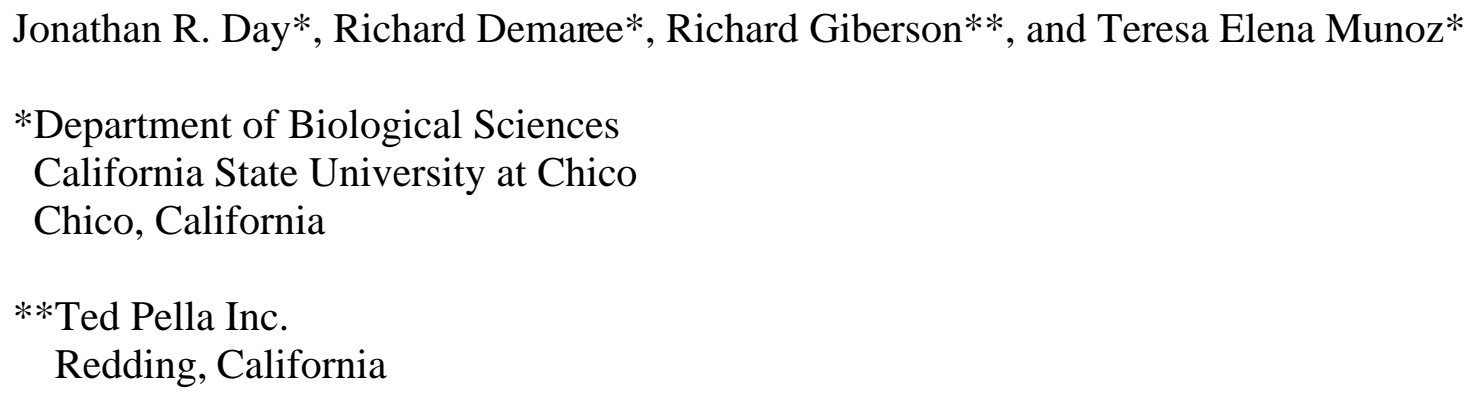

We use Immunocytochemistry to examine proteins within the hippocampus of the ratin vivo and in vitro. This includes determining cell specific and subcellular expression patterns. We also use this tool to monitor changes in the expression after experimental manipulation? Conventional immunocytochemical protocols require primary and secondary incubations of several hours to several days. Reduced signal to noise ratios associated with high background and epitope masking vary with antibody preparations. The advent of variable power microwave ovens with effective temperature control have dramatically reduced these inconsistencies and produced a standardized protocol that can be used with a variety of monoclonal and polyclonal antibodies. It woks equally well with fluorescence and peroxidase-linked detection methods. Finally, there is an astonishing 10-fold reduction in the time required to achieve consistent, reproducible results using this microwave protocol. Simple fluorescence protocols can be completed in less than an hour.

The basic protocol is not fundamentally different from conventional protocols that require overnight antibody incubations, nor are any special solutions required. The protocol we use for peroxidase linked immunocytochemistry on fixed brain sections follows.

4C fix overnight in $4 \%$ paraform

$30 \%$ sucrose equilibration

35 micrometer sliding microtome floating sections

3 rinses PBS @ RT 5 min/ea

$15 \mathrm{~min}$

$120 \mathrm{~s}$

$0.3 \%$ H202@ RT agitate

$20 \mathrm{~min}$

$60 \mathrm{~s}$

3 rinses PBS@RT 5 min/ea

$15 \mathrm{~min}$

$120 \mathrm{~s}$

10\% horse serum/PBS/ 1\% BSA/ 0.3\% triton X-100 (block) @ RT

$30 \mathrm{~min}$

$60 \mathrm{~s}$

Primary antibody in PBS or block @ RT (or overnight@ 4C)

$3 \mathrm{~h}$ or $16 \mathrm{~h} 6 \mathrm{~min}$

3 rinses 1\% block @ RT 15 min/ea

Secondary antibody @ RT

$45 \mathrm{~min}$

$120 \mathrm{~s}$

3 rinses PBS @ RT 15 min/ea

$1 \mathrm{~h}$

$6 \mathrm{~min}$

$\mathrm{ABC}$

$45 \mathrm{~min} \quad 120 \mathrm{~s}$

3 rinses PBS @ RT 10 min/ea

$1 \mathrm{~h} \quad 6 \mathrm{~min}$

2 rinses Imidazole $5 \mathrm{~min} / \mathrm{ea}$

$30 \mathrm{~min} \quad 120 \mathrm{~s}$

DAB for up to

$10 \mathrm{~min} \quad 120 \mathrm{~s}$

Rinse and mount

total time

$7 \mathrm{~min}$

$6 \mathrm{~min}$

$8.5-21.5 \mathrm{~h} \quad 38 \mathrm{~min}$



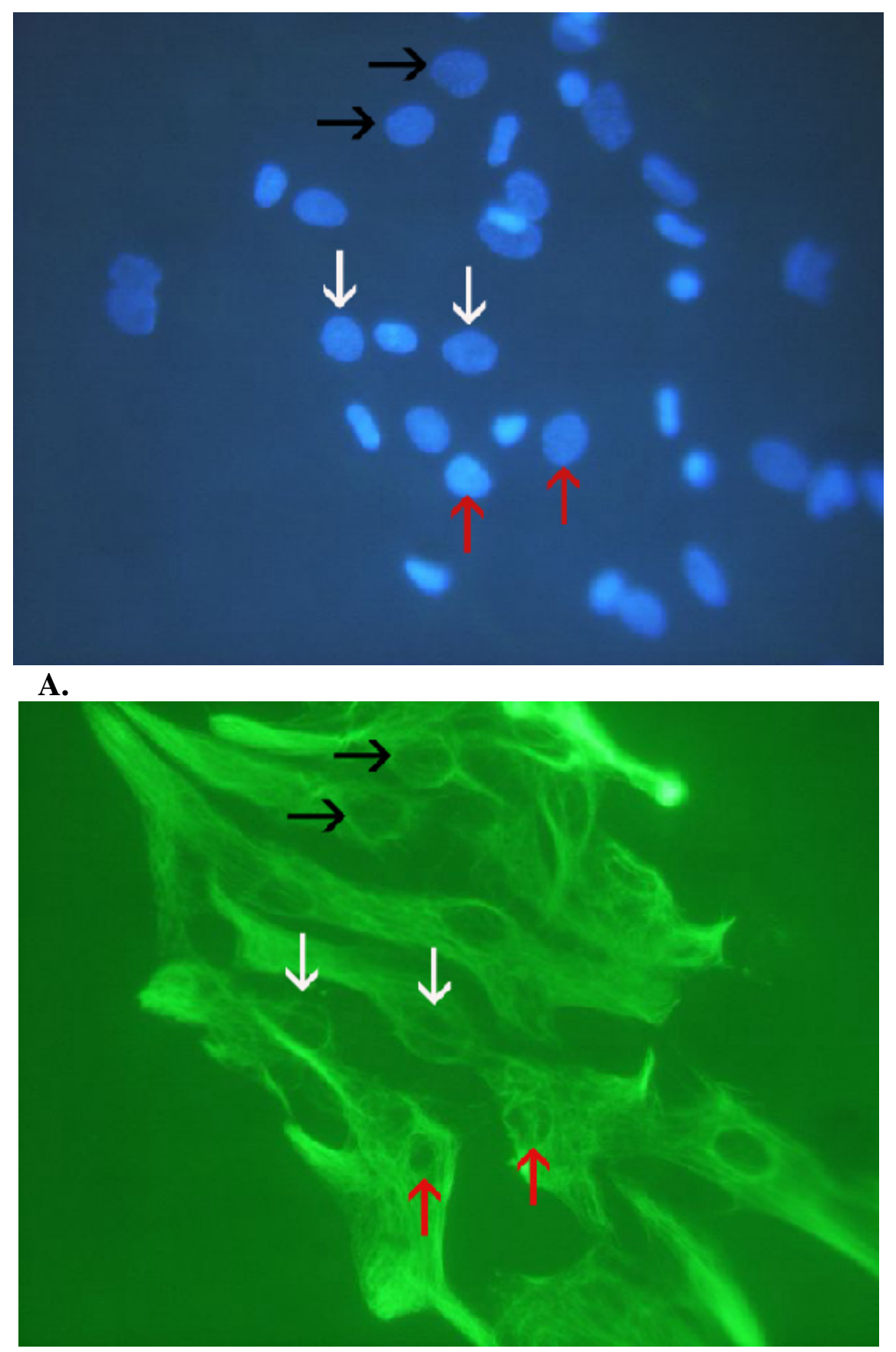

B.

Figure1. shows nuclear profiles of primary astrocytes isolated fromE18 rat cortex after 7 days in vitro revealed by bisbenzamide and UV epifluorescence illumination(A). Panel B shows the same field under blue epifluorescence illumination. Glial fibrillary acidic protein (GFAP) immunoreactivity is revealed using an FITC conjugated secondary antibody to a monoclonal primary antibody directed against a human GFAP epitope. The cells were labeled on the glass coverslips where they were grown using the basic microwave protocol described in the abstract. Arrows of the same color and direction point to the same nuclei in each panel. 